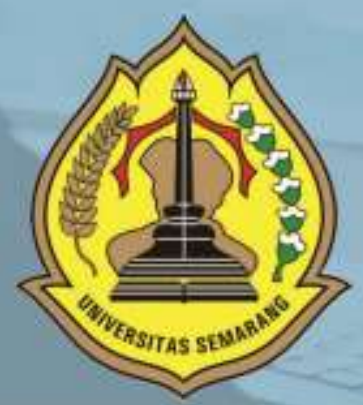

PENGARUH WORK FAMILY CONFLICT, STRES KERJA DAN KEPEMIMPINAN TERHADAP TURNOVER INTENTION KARYAWAN (STUDI PADA SELURUH KARYAWAN BAGIAN PLANNING PRODUCTION AND INVENTORY CONTROL PT. PARKLAND WORLD INDONESIA JEPARA

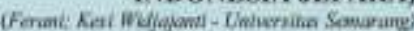

STUDI SOFT SKILL LULUSAN PENDIDIKAN KEJURUAN DI TEMPAT KERJA

Whort-Chiversikio Semorang

ANALISIS IINGKUNGAN INTERNAL DAN EKSTERNAL, PADA UKM PREMIUM PLUS LAUNDRY CABANG MULAWARMAN SEMARANG

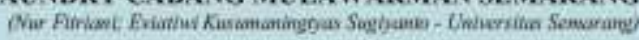

FAKTOR-FAKTOR YANG MEMPENGARUHI PERTIMBANGAN TINGKAT MATERIALITAS AUDIT

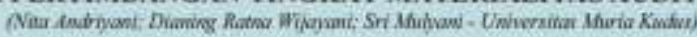

MANAJEMEN LABA DAN FAKTOR-FAKTOR YANG MEMPENGARUHINYA (STUDI EMPIRIS PADA PERUSAHAN MANUFAKTUR DI BEI)

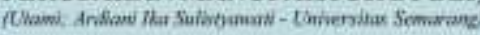

PENDAPATAN ASLI DAERAH, DANA PERIMBANGAN, DAN SISA LEBIH PEMBIAYAAN ANGGARAN TERHADAP PENGALOKASIAN BELANJA MODAL: STUDI PADA KABUPATEN/KOTA DI PROVINSI JAWA TENGAH

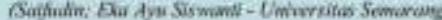

PERSEPSI PENGGUNA JASA TRANS JATENG TERHADAP KUALITAS PELAYANAN ANGKUTAN AGLOMERASI PERKOTAAN TRANS

JATENG

(Studi Kasus Trans Jateng Koridor I Semarang (Tawang) - Bawen)

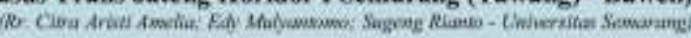

WORTHLESSNESS IS A POWER: MENGAPA ORANG BERSEDIA MENARUH UANG DI APLIKASI GO-PAY

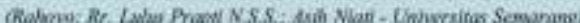

ANALISIS PENGARUH KUALITAS PRODUK, PERSEPSI HARGA, DAN PROMOSI TERHADAP KEPUTUSAN PEMBEIIAN WELLBLUE AL KALINE WATER PITCHER

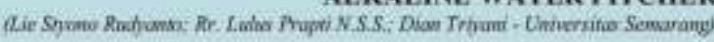

STRATEGI PEMASARAN UNTUK MENINGKATKAN VOLUME PENJUALAN (STUDI KASUS PADA SHOFA CATERING)

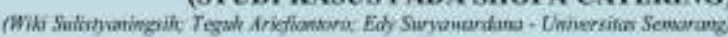

PENGARUH CITRA MEREK, PERSEPSI HARGA, DAN KUALITAS PRODUK TERHADAP KEPUTUSAN PEMBELIAN SEPATU OLAH RAGA MEREK ADIDAS

(Studi di Kota Semarang)

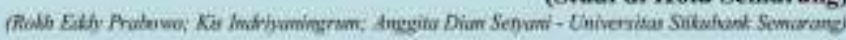

PENGARUH KEMUDAHAN TERHADAP KEPUTUSAN MENGGUNAKAN E-BANKING PADA BNI 46 KC KARANGAYU SEMARANG DENGAN MINAT NASABAH DAN KEPERCAYAAN SEBAGAI VARIABEL. MEDIASI

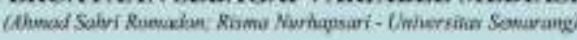

PENELITLAN KEBERLANGSUNGAN USAHA ARDANI INDONESIA SEBAGAI UMKM BERBASIS INDUSTRI KREATIF

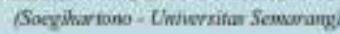

STRATEGI PELAYANAN BUS RAPID TRANSIT (BRT) TRANS SEMARANG

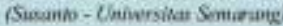

ANALISIS PENGARUH KEPEMIMPINAN, STRES KERJA, DAN LINGKUNGAN KERJA TERHADAP KINERJA KARYAWAN BAGIAN PRODUKSI SEWING PT. SAMWON BUSANA INDONESIA SEMARANG

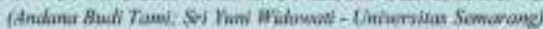




\section{DESKRIPSI}

Majalah IImiah Solusi Mengkaji

Masalah-Masalah Sosial,

Ekonomi dan Bisnis

\section{KETERANGAN TERBIT}

Terbit Pertama Kali Juli 2002

dan SelanjutnyaTerbit Tiga Bulan

Sekali (Januari, April, Juli dan

Oktober)

\section{PENERBIT}

Fakultas Ekonomi USM

\section{ALAMAT PENERBIT}

JL. Soekarno Hatta Semarang

Telp. 024-6702757 Fax. 024-6702272

\section{PENGELOLA}

Editor in Chief : Yohanes Suhardjo, SE, M.Si., Ak, CA Vice Editor Chief : Sugeng Rianto, SE, MM

Managing Editor: Edy Suryawardana, SE, MM

Secretary of Managing Editor : Asih Niati, SE, MM

Administration \& Circulation :

Citra Rizkiana, SE, MM

Layout \& Typesetting : M Burhan Hanif S.Kom, M.Kom

Board of Editors:

1. Prof. Dr. Ir. Kesi Widjajanti, SE, MM (USM)

2. Prof. Drs. Mohammad Nasir, Msi, Ph.D, AK. (USM)

3. Prof. Supramono SE, MBA, DBA (UKSW)

4. Prof. Drs. H. Imam Ghozali, M.Com, Akt, PhD (UNDIP)

5. Prof. Dr. Agus Suroso, MS (UNSOED)

6. Prof. Dr. Widodo, SE, M.Si (UNISSULA)

7. Prof. Dr. Dra. Sulastri, ME, M.Kom (UNSRI)

8. Dr. Ardiani Ika S, SE, MM, Ak, CA, CPA (USM)

\section{KATA PENGANTAR}

Sungguh merupakan kebahagiaan tersendiri bagi kami, takala kami dapat hadir rutin setiap tiga bulan sekali untuk saling bertukar pikiran mengenai hal-hal baru dibidang sosial, ekonomi dan bisnis.

Pada kesempatan ini penerbit menyampaikan terima kasih kepada semua pihak yang telah mengirimkan artikel-artikelnya. Penerbit akan membuka kesempatan seluas-luasnya bagi seluruh kalangan akademisi maupun praktisi baik dari dalam maupun luar Universitas Semarang untuk mempublikasikan karya ilmiahnya.

Penerbitan majalah ilmiah "SOLUSI" kali ini menghadirkan 15 (Lima Belas) artikel yang kami anggap layak untuk diterbitkan, dengan harapan dapat menjadi tambahan referensi bagi para pembaca dan menjadi sumbangan pengembangan persemaian khasanah pengetahuan dibidang sosial, ekonomi dan bisnis.

Akhir kata semoga majalah ilmiah "SOLUSI" dapat memberi manfaat yang sebesar-besarnya.

Hormat Kami 


\section{DAFTAR ISI}

PENGARUH WORK FAMILY CONFLICT, STRES KERJA DAN KEPEMIMPINAN TERHADAP TURNOVER INTENTION KARYAWAN (STUDI PADA SELURUH KARYAWAN BAGIAN PLANNING PRODUCTION AND INVENTORY CONTROL PT. PARKLAND WORLD INDONESIA JEPARA)

(Ferani; Kesi Widjajanti - Universitas Semarang)

STUDI SOFT SKILL LULUSAN PENDIDIKAN KEJURUAN DI TEMPAT KERJA

(Albert - Universitas Semarang)...

ANALISIS LINGKUNGAN INTERNAL DAN EKSTERNAL PADA UKM PREMIUM PLUS

LAUNDRY CABANG MULAWARMAN SEMARANG

(Nur Fitriani; Eviatiwi Kusumaningtyas Sugiyanto - Universitas Semarang)

FAKTOR-FAKTOR YANG MEMPENGARUHI PERTIMBANGAN TINGKAT

MATERIALITAS AUDIT

(Nita Andriyani; Dianing Ratna Wijayani; Sri Mulyani - Universitas Muria Kudus).

MANAJEMEN LABA DAN FAKTOR-FAKTOR YANG MEMPENGARUHINYA

(STUDI EMPIRIS PADA PERUSAHAN MANUFAKTUR DI BEI)

(Utami; Ardiani Ika Sulistyawati - Universitas Semarang)

PENDAPATAN ASLI DAERAH, DANA PERIMBANGAN, DAN SISA LEBIH PEMBIAYAAN ANGGARAN TERHADAP PENGALOKASIAN BELANJA MODAL: STUDI PADA

KABUPATEN/KOTA DI PROVINSI JAWA TENGAH

(Saifudin; Eka Ayu Siswanti - Universitas Semarang).

PERSEPSI PENGGUNA JASA TRANS JATENG TERHADAP KUALITAS PELAYANAN ANGKUTAN AGLOMERASI PERKOTAAN TRANS JATENG

(Studi Kasus Trans Jateng Koridor I Semarang (Tawang) - Bawen)

(Rr. Citra Aristi Amelia; Edy Mulyantomo; Sugeng Rianto - Universitas Semarang)

WORTHLESSNESS IS A POWER: MENGAPA ORANG BERSEDIA MENARUH UANG DI APLIKASI GO-PAY

(Rahoyo; Rr. Lulus Prapti N.S.S.; Asih Niati - Universitas Semarang).

ANALISIS PENGARUH KUALITAS PRODUK, PERSEPSI HARGA, DAN PROMOSI TERHADAP KEPUTUSAN PEMBELIAN WELLBLUE ALKALINE WATER PITCHER

STRATEGI PEMASARAN UNTUK MENINGKATKAN VOLUME PENJUALAN (STUDI KASUS PADA SHOFA CATERING)

(Wiki Sulistyaningsih; Teguh Ariefiantoro; Edy Suryawardana - Universitas Semarang)

PENGARUH CITRA MEREK, PERSEPSI HARGA, DAN KUALITAS PRODUK TERHADAP KEPUTUSAN PEMBELIAN SEPATU OLAH RAGA MEREK ADIDAS

(Studi di Kota Semarang)

(Rokh Eddy Prabowo; Kis Indriyaningrum; Anggita Dian Setyani - Universitas Stikubank Semarang) .121

PENGARUH KEMUDAHAN TERHADAP KEPUTUSAN MENGGUNAKAN E-BANKING PADA BNI 46 KC KARANGAYU SEMARANG DENGAN MINAT NASABAH DAN KEPERCAYAAN SEBAGAI VARIABEL MEDIASI

(Ahmad Sahri Romadon; Risma Nurhapsari - Universitas Semarang) 
PENELITIAN KEBERLANGSUNGAN USAHA ARDANI INDONESIA SEBAGAI UMKM BERBASIS INDUSTRI KREATIF

(Soegihartono - Universitas Semarang)

STRATEGI PELAYANAN BUS RAPID TRANSIT (BRT) TRANS SEMARANG

(Susanto - Universitas Semarang).....

ANALISIS PENGARUH KEPEMIMPINAN, STRES KERJA, DAN LINGKUNGAN KERJA TERHADAP KINERJA KARYAWAN BAGIAN PRODUKSI SEWING PT. SAMWON BUSANA INDONESIA SEMARANG

(Andana Budi Tami; Sri Yuni Widowati - Universitas Semarang). 


\title{
STRATEGI PEMASARAN UNTUK MENINGKATKAN VOLUME PENJUALAN
}

\section{(STUDI KASUS PADA SHOFA CATERING)}

\author{
Wiki Sulistyaningsih ${ }^{1}$ \\ Teguh Ariefiantoro ${ }^{2}$ \\ Edy Suryawardana ${ }^{3}$
}

Wikisulistya11@gmail.com ${ }^{1}$

Fakultas Ekonomi Universitas Semarang

Diterima: Agustus 2020, Disetujui: September 2020, Dipublikasikan: Oktober 2020

\begin{abstract}
This research was conducted in Shofa Catering Wolter Monginsidi Pedurungan Semarang. The purpose of this study was to determine the marketing strategies applied by Shofa Catering in increasing sales volume and how to deal with competition in similar businesses. The strategy used by Shofa Catering is to use the 4p marketing mix, namely product, price, promotation, place.

This study used a qualitative method, in this study using a data reliability test in the form of source triangulation and method triangulation. With the number of informants 5 people including the owner, 2 employees, and 2 consumers. From the results of this study, it can be seen that the marketing strategy that uses 4 p, namely product, price, promotation, place, the strategy used by entrepreneurs has worked well. Where these four variables support and complement each other, so as to increase the sales volume of Shofa Catering.
\end{abstract}

Keywords: 4p Marketing Mix, Sales Volume

Penelitian ini dilakukan di usaha Shofa Catering Wolter Monginsidi Pedurungan Semarang. Tujuan dari penelitian ini adalah untuk mengetahui strategi pemasaran yang diterapkan Shofa Catering dalam meningkatkan volume penjualan dan cara bagaimana menghadapi sebuah persaingan pada usaha yang sejenis. Strategi yang digunakan oleh Shofa Catering ialah menggunakan bauran pemasaran $4 \mathrm{p}$ yaitu product, price, promotation, place.

Penelitian ini menggunakan metode kualitatif, dalam penelitian ini menggunakan Uji Kedibilitas data berupa trianggulasi sumber dan trianggulasi metode. Dengan jumlah informan 5 orang yang meliputi pemilik, 2 karyawan, dan 2 konsumen. Dari hasil penelitian ini dapat diketahui bahwa strategi pemasaran yang menggunakan $4 \mathrm{p}$ yaitu product, price, promotation, place, strategi yang digunakan oleh pengusaha sudah berjalan dengan baik. Dimana keempat variabel ini saling mendukung dan melengkapi, sehingga dapat meningkatkan volume penjualan Shofa Catering.

Kata Kunci : Bauran Pemasaran 4p, Volume Penjualan 


\section{LATAR BELAKANG}

Peran usaha sekarang sangat penting dalam membangun perekonomian di Indonesia. Terutama dalam penyediaan tenaga kerja dan sumber penghasilan bagi kelompok masyarakat yang berpenghasilan rendah. Sektor usaha memiliki peran yang sangat strategis baik sosial ekonomi dan politis dengan menyediakan barang dan jasa bagi konsumen berdaya beli rendah sampai dengan sedang. Setiap perusahaan, baik yang bergerak di bidang produk ataupun jasa, mempunyai tujuan untuk tetap hidup dan berkembang. Kondisi pertumbuhan bisnis sekarang ini cukup tinggi, dimana dapat dilihat dari tumbuhnya perusahaan-perusahaan dengan produk yang sejenis sebagai pesaing, sehingga akan terjadi persaingan dalam memperebutkan pangsa pasar dan konsumen.

Salah satu bentuk usaha yang dapat di kembangkan yaitu dengan mendirikan usaha UMKM (Usaha Mikro Kecil Menengah) yaitu dijelaskan dalam UU No. 20/2008, pada Undang-Undang tersebut bahwa UMKM adalah perusahaan kecil yang dimiliki dan dikelola oleh seseorang atau dimiliki oleh sekelompok kecil orang dengan jumlah kekayaan dan pendapatan tertentu. Dilansir dari situs CNN Indonesia, Komite Ekonomi dan Industri dan Industri Nasional (KEIN) menyebutkan bahwa UMKM adalah sektor yang memiliki potensi besar. Kalau menurut data Kementrian Koperasi dan UMKM, sekitar 98,7\% usaha di Indonesia merupakan usaha mikro. Tidak mengherankan apabila UMKM berkontribusi terhadap produk Domestik Bruto (PDB) Indonesia hingga mencapai 36,82\%. (CNN Indonesia 28/05/2019)

Tabel 1. 1 Data Penjualan Shofa Catering 2017 - 2019

Tahun
2017
2018
2019

\section{Penjualan}

Rp. 445,602,400.-

Rp. 698, 596,000.-

Rp. 881,516,900.-
Presentase

$56,77 \%$

$26,18 \%$

Sumber: Shofa Catering, 2020

Berdasarkan pada data Tabel 1.1 di atas bisa dilihat, pendapatan pada Shofa Catering disetiap tahunnya mengalami peningkatan pendapatan pada tahun 2017 sebesar Rp. 445.602.000, kemudian pendapatan pada tahun 2018 sebesar Rp.698,596.000, dan mengalami peningkatan kembali pada tahun 2019 sebesar Rp.881.516.900. Pada table diatas dengan selalu meningkatnya jumlah penjualan di setiap tahun, maka tentu saja akan memberikan dampak positif pada usaha catering tersebut. Dengan demikian perusahaan dapat lebih berusaha lagi agar tetap bisa mempertahankan pendapatan tersebut sehingga tidak mengalami penurunan, serta dapat terus meningkatkan pendapatan.

Berdasarkan masalah diatas dapat diturunkan ke dalam beberapa pertanyaan penelitian sebagai beriku :

1. Bagaimana strategi pemasaran yang selama ini diterapkan untuk meningkatkan volume penjualan pada Shofa Catering? 
2. Bagaimana upaya yang dilakukan pada Shofa Catering dalam menghadapi sebuah persaingan pada usaha yang sejenis?

\section{TINJAUAN PUSTAKA}

\section{Volume Penjualan}

Swastha dan Sahaja (2014:246) penjualan adalah suatu proses pertukaran barang atau jasa antar penjual dan pembeli.

\section{Pemasaran}

Kotler \& Keller (2012) mendefinisikan pemasaran adalah suatu fungsi organisasi dan serangkaian proses untuk menciptakan, mengkomunikasikan, dan memberikan nilai kepada pelanggan dan untuk mengelola hubungan pelanggan dengan cara yang menguntungkan organisasi dan pemangku kepentingannya.

\section{Strategi Pemasaran}

Kotler dan Amstrong (2014:72) Strategi pemasaran merupakan logika pemasaran yang dapat digunakan oleh perusahaan dengan harapan agar unit bisnis dapat mencapai tujuan perusahaan.

\section{Bauran Pemasaran}

Kotler dan Armstrong (2012:75), Bauran pemasaran adalah kumpulan alat taktis, yang terkendali (produk, harga, tempat, dan promosi) yang dipadukan perusahaan untuk menghasilkan respon yang diinginkannya di pasar sasaran.

Bauran pemasaran menurut Kotler dan Armstrong (2014:19) dibagi menjadi beberapa veriabel yang sesuai dengan unsur-unsur dan pengertiannya masing-masing, digolongkan menjadi 4 yaitu:

1. Product ( Produk)

Menurut Kotler dan Armstrong dalam Tanzil (2014:7) yaitu produk adalah mengelola unsur produk termasuk perencanaan dan pengembangan barang atau jasa yang tepat untuk dipasarkan dengan mengubah barang atau jasa yang ada dengan menambah dan mengambil tindakan yang lain yang mempengaruhi bermacammacam barang atau jasa.

2. Price ( Harga )

Menurut Kotler dan Armstrong (2014:7), harga adalah suatu sistem menejemen perusahaan yang akan mementukan harga dasar yang tepat bagi produk barang atau jasa dan harus menentukan strategi yang menyangkut potongan harga, pembauran ongkos angkut dan berbagai variable yang bersangkutan.

3. Promotation ( Promosi)

Menurut Kotler dan Armstrong (2014:7), promosi adalah suatu unsur yang digunakan untuk memberitahukan dan membujuk pasar tentang produk yang baru pada perusahaan melalui iklan, penjualan pribadi, promosi penjualan maupun publikasi melalui saluran media-media komunikasi seperti media massa, media cetak dan media elektronik.

4. Place ( Lokasi ) 
Menurut Utami (2012) Lokasi adalah struktur fisik dari sebuah usaha yang merupakan komponen utama yang terlihat dalam membentuk kesan sebuah usaha yang dilakukan perusahaan dalam melakukan penetapan usahanya dan kegiatan dalam memberikan sebuah layanan yang dibutuhkan oleh konsumen.

\section{Alur Penelitian}

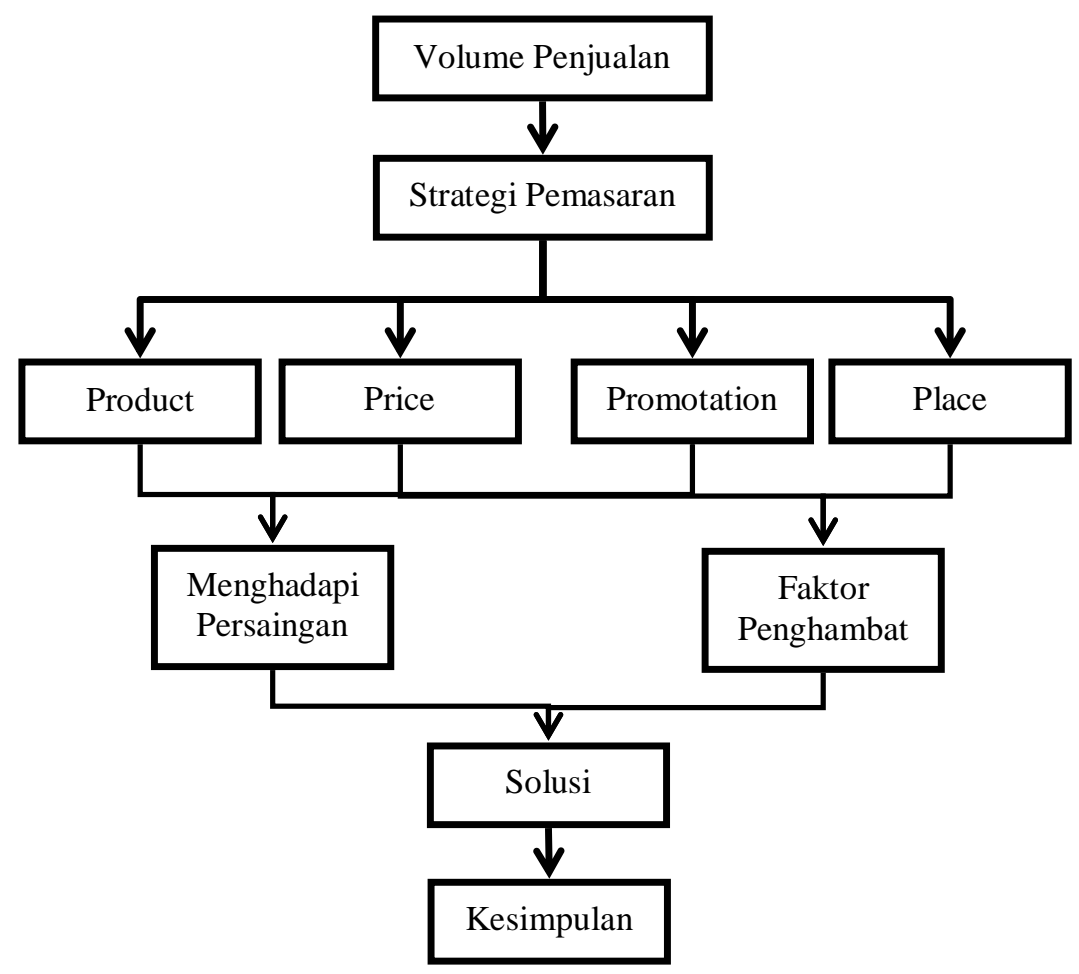

\section{METODE PENELITIAN}

\section{Jenis Penelitian}

Jenis penelitian ini adalah dilakukan dengan menggunakan pendekatan kualitatif, Karena penelitian ini dilakukan dengan cara riset yang bersifat deskriptif dan cenderung menggunakan analisis. Serta bertujuan untuk menggambarkan realita sosial yang komplek dengan menerapkan konsep-konsep teori yang telah ada.

\section{Tempat Dan Waktu Penelitian}

Lokasi penelitian dilakukan di Jalan Kyai Abdul Manan Rt.06 Rw.04 Woltermonginsidi Pedurungan Kota Semarang. Waktu penelitian dilaksanakan pada bulan Maret 2019 dalam kurun waktu kurang lebih 3 bulan. 


\section{Jenis Data Penelitian}

Adapun jenis-jenis data yang digunakan di dalam penelitian kualitatif yaitu terdiri dari 2 jenis sumber data yang bersumber dari :

A. Data Primer

Menurut Sugiono (2016) sumber primer adalah sumber data langusng memebrikan data kepada pengumpulan data.

B. Data Sekunder

Menurut Sugiono (2016) sumber sekunder merupakan sumber yang tidak langsung memberikan data kepada pengumpulan data, misalnya lewat otang lain atau lewat dokumen.

\section{Metode Pengumpulan Data}

1. Wawancara

Menurut Susan Stainback (1988) dalam Sugiono (2016), mengemukakan bahwa interviewing provide the researcher a means to gain a deeper understanding of how the participant interpret a situation or phenomenon than can be gained through observation alon.

\section{Observasi}

Menurut Marshall (1995) dalam Sugiono (2016) menyatakan bahwa, "through observation, the researcher learn about behavior and the meaning attached to thouse behavior". Melalui observasi, peneliti belajar tentang perilaku, dan makna dari perilaku tersebut.

3. Dokumentasi

Dokumentasi menurut Sugiono (2013) dokumen merupakan catatan peristiwa yang sudah berlalu. Dokumen dapat berbentuk tulisan, gambar, atau karya-karya monumental dari seseorang.

\section{HASIL PENELITIAN DAN PEMBAHASAN}

\section{Deskripsi Objek}

Pada objek penelitian ini diambil dari usaha rumahan UMKM yaitu usaha Catering "Shofa Catering" yang beralamat di Jl. Kyai Abdul Manan Rt.06 Rw.04 Wolter Monginsidi, Pedurungan, Semarang, Jawa Tengah. Awal mula perjalanan usaha catering ini dimulai dari ibu si pemilik catering ini, beliau awalnya hanya membantu sang ibu untuk memenuhi pesananan catering tersebut. Dulu selain usaha catering makanan, beliau juga menyewakan peralatan masak untuk acara hajatan, namun setelah ibunya meninggal beliau lah yang meneruskan usaha catering tersebut.

Beliau selalu berupaya untuk selalu mengembangkan usahanya tersebut tidak hanya di pemenuhan pesanan catering rumahanan saja tetapi merambah ke acara-acara wedding dan acara pertemuan lainnya. 


\section{Strategi Marketing Mix yang diterapkan Pada Usaha Shofa Catering}

Strategi pemasaran yang digunakan oleh Shofa Catering dalam meningkatkan volume penjualannya ialah dengan menggunakan $4 \mathrm{p}$ yaitu product, price, promotation, place.

\section{Produk ( Product)}

Dari hasil wawancara dengan para narasumber bahwa produk atau makanan yang diberikan oleh Shofa Catering sangat terjamin kebersihannya dan juga enak untuk dinikmati. Shofa Catering selalu berupaya untuk memberikan produk yang berkualitas kepada konsumen serta berupaya memenuhi pesanan konsumen, selain itu Shofa Catering selalu berinovasi dengan makanan-makananya ataupun dengan produk kemasannya. Dengan demikian dapat menarik minat konsumen jika produk atau kemasan yang ditawarkan terlihat menaik dan berbeda dengan yang lainnya.

2. Harga (Price)

Hasil observasi dilapangan kepada konsumen, pemilik serta karyawan bahwa harga yang diterapkan oleh Shofa Catering tidak terlalu mahal dan juga tidak terlalu murah, semua masih mengikuti harga pasaran. Pihak pengusaha juga tidak akan menurunkan harga bila mana keinginan masih bisa masuk dalam perhitungan harga, tenaga, bahan bakunya.

3. Promosi ( Promotation)

Berdasarkan hasil wawancara yang telah dilakukan di Shofa Catering promosi yang dilakukan dengan cara berkerjasama dengan pihak-pihak lain, mengadakan pameran-pameran, membagikan brosur, memanfaatkan media sosial seperti Instagram untuk memberikan informasi terbaru kepada caloncalon konsumen, dan dari mulut ke mulut pelanggan yang pernah menggunakan jasa Shofa Catering.

4. Lokasi ( Place)

Berdasarkan survey ke lokasi usaha menurut peneliti bahwa tempat usaha Shofa Catering ini sangatlah mudah diakses serta terdapat parkir yang cukup luas, tertera juga di google maps, dan terdapat plang nama usaha.

\section{PENUTUP}

\section{Kesimpulan}

Dari hasil penelitian ini dapat diketahui bahwa strategi pemasaran yang menggunakan $4 \mathrm{p}$ yaitu product, price, promotation, place, strategi yang digunakan oleh pengusaha sudah berjalan dengan baik. Dimana keempat variabel ini saling mendukung dan melengkapi, sehingga dapat meningkatkan volume penjualan Shofa Catering.

\section{Saran}

1. Mengubah akun Instagram Shofa Catering dari akun pribadi menjadi akun khusus bisnis dengan cara menjalin kerjasama oleh pihak Instagram untuk mengiklankan produk atau jasa. Maka dari situ tanpa mencari nama Shofa Catering akan muncul di 
mana saja sesuai target yang telah diatur, promosi melalui media sosial bisa meningkatkan branding bisnis, semakin dikenal banyak orang maka semakin banyak orang yang menggunakan dan keuntungan yang didapat semakin besar.

2. Lebih meningkatkan lagi dalam hal promosi, seperti promosi melalui iklan radio. Dengan cara itu nama usaha Shofa Catering bisa lebih dikenal lagi oleh kalangan masyarakat.

\section{DAFTAR PUSTAKA}

Adam Fauzi dan Eddy Poernomo. "Strategi Pemsaran Dalam Meningkatkan Omset Pada Supermarket Bahan Bangunan Mitra 10 Surabaya”. Jurnal Manajemen Jaya Negara, ISSN: 2548-9330, Vol. 9 Nomor 1 Maret Tahun 2017.

Dewi Jayanti Mandasari, Joko Widodo, Sutrisno Djaja. "Strategi Pemasaran Usaha Mikro, Kecil Dan Menengah (UMKM) Batik Magenda Tamanan Kabupaten Bondowoso". Jurnal Ilmiah Ilmu Pendidikan, Ilmu Ekonomi, Dan Ilmu Sosial, ISSN 1907-9990, Vol. 13 Nomor 1 Hal 123 Tahun 2019.

Firna M. A. Poluan, Silvya L. Mandey, Imelda W.J. Ogi. "Strategi Marketing Mix Dalam Meningkatkan Volume Penjualan (Studi Pada Minuman Kesehatan Instant Alvero)"'. Jurnal EMBA, ISSN: 2303-1174, Vol. 7 Nomor 3 Hal 2969-2978 Juli 2019.

http//:Hestanto.web.id/bauran-pemasaran-marketing-mix/

http//:Kamus.tokopedia.com/h/harga

Http//:dimaspurnama25.blogspot.com/2016/09/ekonomi.html

Jaya Bahwiyanti dan Suggiannor. "Strategi Pemasaran Untuk Meningkatkan Penjualan

Pada CV. PARIS BANJARBARU”. Jurnal Ilmiah Ekonomi dan Bisnis, ISSN 2615-

2134, Jilid 4, Nomor 2018, Hal 058-068 Tahun 2018.

Repository.unisba.ac.id:8080/xmlui/bitstream/handle/123456789/572/06bab2pdf

Sugiyono. 2016. Metode Penelitian Kualitatif, Alfabeta: Bandung.

Wahyu Sri astutik\&Kartika Piniji Dwi B. "Strategi Pemasaran Terhadap Peningkatan

Volume Penjualan (Studi pada perusaan Unilever Tbk tahun 2015-2019)”. Jurnal

Pemasaran, ISSN 2615-3505, Vol.14, Nomor 03, Hal 2085 Tahun 2019. 